\title{
Arquitectura carcelaria y presos en las provincias de León y Zamora \\ a comienzos del siglo XIX
}

\section{Prison architecture and prisoners in the provinces of León and Zamora at the beginning of the $19^{\text {th }}$ century}

\author{
María José PÉREZ ÁLVAREZ \\ Departamento de Historia. Facultad de Filosofía y Letras \\ Universidad de León \\ maria-jose.perez@unileon.es
}

Recibido: 28 de octubre de 2011

Aceptado: 16 de enero de 2012

\section{RESUMEN}

Los informes elaborados en las provincias de León y Zamora, en respuesta a la solicitud realizada por la Secretaría de Cámara y Gobierno de las salas del crimen de la Real Chancillería de Valladolid, en 1817, nos ha permitido acercarnos a la infraestructura carcelaria de esos territorios. Aquel había surgido de la necesidad, impulsada por la Corona, de llevar a cabo un programa de adecuación de la red carcelaria. Aunque la mayor parte de las cuestiones que se plantearon hacían referencia a la arquitectura del edificio, algunas de ellas tuvieron un enfoque más social.

PALABRAS CLAVE: Antiguo Régimen, León, Zamora, cárcel, seguridad.

\begin{abstract}
The reports on the provinces of León and Zamora which written in response to a request from the Chamber and Government Office of the Valladolid Royal Chancery criminal courts in 1817 have provided us with an understanding of the prison infrastructure in these two provinces. This infrastructure had emerged in response to the need, instigated by the Crown, to implement a programme of reorganization of the prison system. Although the majority of the reforms proposed referred to the architecture of the buildings, some of them were more socially oriented.
\end{abstract}

KEYWORDS: Old Regime, León, Zamora, prison, security.

\section{RÉSUMÉ}

Les rapports produits dans les provinces de León et de Zamora, en réponse à la demande formulée par le Secrétaire du gouvernement des conseils du crime de la Chancellerie Royale de Valladolid, en 1817, nous ont permis de nous rapprocher de l'infrastructure pénitentiaire dans ces territoires. La consulte avait surgi de la nécessité, motivée par la Couronne, de mener un programme d'adaptation du réseau des prisons. Bien que la plupart des questions qui furent soulevées faisaient référence à l'architecture du bâtiment, certaines d'entre elles avaient une approche plus sociale.

MOTS CLÉ : Ancien régime, León, Zamora, prison, sécurité. 


\section{ZUSAMMENFASSUNG}

Die in den Provinzen León und Zamora erstellten Rapporte, die 1817 von Seiten des Sekretariats der Ständekammer und der Regierung von den Gerichten der Königlichen Kanzlei von Valladolid angefordert worden waren, erlauben es, mehr über die Gefängnisinfrastruktur dieser Regionen zu erfahren. Diese war aus der Notwendigkeit geboren, ein Programm der Krone zur Reform der Gefängnisorganisation aufzulegen. Obwohl sich die meisten Fragen mit der Gebäudearchitektur befassen, begegnen gleichfalls sozial ausgerichtete Schwerpunkte.

SCHLÜSSELWÖRTER: Altes Reich, León, Zamora, Gefängnis, Sicherheit.

SUMARIO: Introducción. 1. La red carcelaria en las provincias de León y Zamora. A. Las cárceles urbanas. B. Las cárceles de las villas. C. Las cárceles del mundo rural. 2. La seguridad y salubridad de las cárceles. 3. Los alcaides. 4. Los presos.

\section{Introducción}

Durante el Antiguo Régimen ${ }^{1}$, el paso por la cárcel simplemente suponía el primer destino para todos aquellos que habían infringido la ley y que esperaban la actuación de la justicia. Desde la Baja Edad Media, al menos, hasta el triunfo del liberalismo, la estancia en aquellas instalaciones, y la consecuente privación de libertad, no era considerada como un castigo, salvo cuando se trataba de expiar delitos menores o saldar deudas. La misión de las cárceles era custodiar a los presos ${ }^{2}$ mientras durara el periodo procesal, por lo tanto, cumplían una función de depósito³. Esa situación era la consecuencia de aplicar una ley garantista, es decir, no se consideraba delincuentes a los encarcelados hasta que no se dictara una sentencia inculpatoria. Si se confirmaba la transgresión de la ley, entonces se aplicaban las penas ${ }^{4}$, que pasaron del castigo físico a redimirse por medio del trabajo, ya fuera en las galeras o, poste-

\footnotetext{
${ }^{1}$ Este trabajo forma parte de un proyecto de investigación titulado Marginación y respuesta social en el Noroeste de la Península Ibérica durante el Antiguo Régimen, financiado por el Ministerio de Ciencia e Innovación (Ref. HAR2010-17780).

${ }^{2}$ Vid. M. de Lardizábal Uribe, "Discurso sobre las Penas contraído a las Leyes Criminales de España, para facilitar su reforma", Revista de Estudios Penitenciarios, 174, 1966, pp. 627-745, (ed. orig. 1782); J. Serna Alonso, Presos y pobres en la España del siglo XIX: la determinación social de la marginación, Barcelona, 1988, pp. 135-136. Sobre el significado social del paso de una prisión custodia a una la prisión castigo, Vid. M. Foucault, Vigilar y castigar. Nacimiento de la prisión, Méjico, 1976, pp. 233 y 234.

${ }^{3}$ No ocurría lo mismo con las cárceles destinadas a eclesiásticos o a enemigos del poder real. F. Burgos Fernández, "Evolución histórica de la legislación penitenciaria en España", Anales de la Universidad de Cádiz, 11, 1996, pp. 253-266.

${ }^{4}$ Las penas impuestas por la justicia debían de tener la suficiente envergadura para resarcir a la víctima, a la sociedad y al monarca, por lo que su alcance de ninguna manera podía ser proporcionado al delito. J.L. Heras Santos, "Los galeotes de los Austrias: la penalidad al servicio de la Armada", Historia Social, 6, 1990, pp. 127-140. A su vez, la justicia era uno de los instrumentos por los que la autoridad real se proyectaba entre los súbditos. P. Trinidad Fernández, "Penalidad y gobierno de la pobreza en el Antiguo Régimen”, Estudios de Historia Social, 48/48, 1989, p. 7-64.
} 
riormente, en minas, obras públicas o astilleros. Cualquiera de éstas medidas utilitaristas $^{5}$, todas ellas con un resultado económico, se adoptaron en beneficio de la corona.

El pensamiento surgido de la corriente ilustrada del siglo XVIII traería consigo importantes novedades en el ámbito carcelario, pero no todas fueron originales, pues ya en centurias precedentes se habían ido avanzando algunas cuestiones. Entre los nuevos y humanizadores proyectos que se esperaba poner en marcha estaban, entre otros, conceder garantías jurídicas a los presos, la remisión de los trabajos forzados o considerar la privación de libertad como un castigo ${ }^{6}$. Este último suponía retomar el planteamiento humanista de las casas de trabajo, que en su momento habían defendido Giginta ${ }^{7}$ o Pérez de Herrera ${ }^{8}$, y que aquel momento se habían creado en algunos países europeos ${ }^{9}$. Entre los representantes de la nueva corriente destacarían John Howard ${ }^{10} \mathrm{o}$ Beccaria ${ }^{11}$. El primero, a finales del siglo XVIII, después de visitar un gran número de establecimientos carcelarios europeos, puso de manifiesto las lamentables condiciones de vida que sufrían los confinados ${ }^{12}$. Es necesario incidir, de nuevo, entre las conexiones existentes entre humanistas e ilustrados. En España, alguno de los representantes de la corriente del siglo XVI ya se había hecho eco de las penurias que debían de afrontar los pobres en las cárceles y los vicios del sistema; así como de algunos posibles remedios para poder paliarlos ${ }^{13}$. De todos modos, las propuestas de unos y otros apenas tuvieron incidencia inmediata en la práctica penitenciaria.

\footnotetext{
${ }^{5}$ Las sanciones penales basadas en el utilitarismo tenían un doble propósito, por un lado, regenerar al preso, ya fuera cumpliendo un servicio al estado o a la administración local en aquellos destinos más duros y menos demandado por las personas libres, y, por otro, satisfacer los intereses de la monarquía. H. Roldán Barbero, Historia de la Prisión en España, Barcelona, 1988, pp. 51 y ss.; P. Trinidad Fernández, La defensa de la sociedad. Cárcel y delincuencia en España (siglos XVIII-XX), Madrid, 1991, p. 29; Á. Alloza, La vara quebrada de la justicia. Un estudio histórico sobre la delincuencia madrileña entre los siglos XVI y XVII, Madrid, 2000, p. 251; R. Iglesias Estepa, Crimen, criminales y reos. La delincuencia y su represión en la antigua provincia de Santiago entre 1700 y 1834, Santiago, 2007, pp. 272-279.

${ }^{6}$ B. Mapelli Caffarena y J. Terradillos Basoco, Sistema de sanciones en el derecho penal, Sevilla, 1989.

${ }^{7}$ M. Giginta, Tratado de remedio de pobres, Barcelona, 2000 (ed. orig. 1579).

${ }^{8}$ C. Pérez de Herrera, Discurso del Amparo de los legítimos pobres y reducción de los fingidos, Madrid, 1975 (ed. orig. 1598).

${ }^{9}$ Respecto a las casas de trabajo surgidas en Europa en el siglo XVI vid. D. Melossi y M. Pavarini, Cárcel y fábrica. Los orígenes del sistema penitenciario (siglos XVI-XIX), México, 1980.

${ }^{10} \mathrm{~J}$. Howard, El estado de las prisiones en Inglaterra y Gales. Estudio introductorio de García Ramírez, México, 2003 (ed. orig. 1777).

${ }^{11}$ C. Beccaria, Tratado de los delitos y de las penas, Madrid, 1774.

${ }^{12}$ En España visitó las prisiones, asilos u hospitales, entre otros, de Burgos, Valladolid, Madrid o Badajoz. J. Howard, El estado de las prisiones en Inglaterra ..., pp. 337-349. Para conocer la repuesta, a las denuncias realizadas por Howard, de los gobernantes y tratadistas europeos del momento, puede consultarse, entre otras obras, las siguientes: D. Melossi y M. Pavarini, Cárcel y fábrica ...; M. J. Moutinho Santos, A sombra e a luz. As prisões do Liberalismo, Porto 1999; J. Serna Alonso, Presos y pobres en la España ..., pp. 109 y ss.

${ }^{13}$ Sobre las teorías de esos tratadistas y la proyección de las mismas, Vid. F. Cadalso, Instituciones Penitenciarias y similares en España, Madrid, 1922; E. Sanz Delgado, "Las viejas cárceles: evolución de
} 
Al margen del cometido que tuvieran las cárceles de Antiguo Régimen, es decir, que fueran utilizadas como recinto de estancia provisional o como instrumento de castigo, el simple hecho de estar confinado en ellas implicaba estar sometido a penalidades físicas tan duras - mala alimentación, falta de higiene, hacinamiento en el caso de las más grandes...- que bien podían equipararse con el cumplimiento de la condena. Nuestra pretensión, en este trabajo, es acercarnos a estas cuestiones a través de una fuente de gran interés: el informe solicitado por la secretaría de cámara y gobierno de las salas del crimen de la Real Chancillería de Valladolid a las cabezas de partido de las provincias que estaban bajo su jurisdicción, el 21 de mayo de 1817 . Este expediente aporta un importante volumen de información sobre la infraestructura carcelaria de aquel momento. Sobre la base de la información allí reflejada, acometeremos el análisis de las características de la red carcelaria en las provincias de León, Zamora y Toro ${ }^{14}$. El patrón de organización extraído de ese informe, dado el pequeño tamaño de esos núcleos de población y su escaso dinamismo económico, es muy posible que fuera, en gran medida, el que estuvo vigente a lo largo del Antiguo Régimen en esos territorios y, muy probablemente, en gran parte de los de la Corona. A su vez, hemos de tener en cuenta que en aquel documento solamente se reflejan las prisiones públicas, pues en ningún caso se registraron las de aquellas instituciones que tenían las suyas propias, como, por ejemplo, las del clero.

La recopilación de todo ese volumen de información sería una de las fases del programa de adecuación del sistema penitenciario, que había sido iniciado por Carlos IV y continuado por Fernando VII. Con esa finalidad, el segundo monarca expidió en 1814 una Real Cédula, en cuyo contenido se recogía, entre otras cuestiones, realizar una investigación sobre el estado de la red carcelaria española ${ }^{15}$. La respuesta, por parte de las justicias locales, que eran quienes debían de ejecutarla, parece que fue bastante deficitaria, pero, independientemente de ese alcance, todas ellas pusieron de manifiesto lo mal dotadas que estaban las Audiencias en el campo de las infraestructuras carcelarias. Aquel proyecto no surgía de una iniciativa original de los monarcas españoles, sino que se encuadraba en un marco europeo, en el que las condiciones de vida carcelaria eran objeto de debate ideológico y reformador.

Para realizar la investigación encargada por Fernando VII, al objeto de valorar la situación de la red carcelaria, se elaboró un formulario con nueve cuestiones, a las que debían de responder las autoridades de cada localidad. El formulario puede divi-

las garantías regimentales", Anuario de Derecho Penal y Ciencias Penales, 56, 2003, pp. 253-352. P. Trinidad Jiménez, "La reforma de las cárceles en el siglo XIX: las cárceles de Madrid", Estudios de Historia Social, 22-23, 1982, pp. 69-189. A partir de ese contexto de denuncia surgiría la ciencia penitenciaria como parte del derecho penal. R. M. Pérez Marcos, Un tratado de derecho penitenciario del siglo XVI. La visita de la cárcel y de los presos de Tomás Cerdán de Tallada, Madrid, 2005.

${ }^{14}$ A.CH.V. (Archivo de la Chancillería de Valladolid), Causas Secretas, Cajas 0045.002 y 0046.0003. Los datos de Zamora y Toro, que se recogieron en el mismo expediente, los hemos tratado en conjunto. ${ }^{15}$ J. Serna Alonso, Presos y pobres en la España..., pp. 129-130. 
dirse en tres partes: una de ellas dedicada las instalaciones para custodiar a los presos, que era la más extensa por ser ese objeto de información, otra al alcaide y la más escueta a los presos, por lo que directamente apenas se tocaron cuestiones relacionada con aspectos sociales. En la primera, se recababa información sobre cómo eran los edificios, su tamaño, el número de celdas que tenían, la seguridad y salubridad de los mismos o su estado de conservación. En la segunda, se requería información sobre la existencia o no de un alcaide, cómo le pagaban el salario y si en la cárcel había un espacio habilitado para él. Finalmente, y en lo que se refiere a los reclusos, solamente se interesaban por la procedían los fondos para costear su alimentación. Toda esta masa informativa debía remitirse al corregidor de la cabeza de partido, para que, una vez recopilada, elaborara un pequeño informe sobre su demarcación.

Esos expedientes, por la amplia información que ofrecen, resultan, sin duda, de gran utilidad, pero antes de abordar su estudio debemos de realizar una serie de precisiones. En primer lugar, no podemos calcular las densidades carcelarias en los territorios estudiados, pues los datos corresponden a las circunscripciones provinciales de Antiguo Régimen, que no coinciden exactamente con las emanadas de las reformas liberales ${ }^{16}$. Así mismo, no aparece información de grades jurisdicciones que estaban bajo dominio señorial. Por otro lado, y en lo que se refiere al estado de las instalaciones, la fecha de elaboración del informe resulta determinante, pues se confeccionó poco tiempo después de la Guerra de Independencia, por lo que las secuelas de aquel conflicto serían evidentes. No son extraños los testimonios de las justicias aludiendo a la destrucción de la cárcel por las tropas francesas o a la falta de unas garantías de seguridad mínimas por la requisa de material durante el conflicto. Por ejemplo, en las localidades leonesas de Villamañán o Bembibre se quejaban de que el lamentable estado de la cárcel lo habían causado los incendios provocados por las tropas napoleónicas. Por su parte, en las zamoranas de Bóveda de Toro, Manganeses de la Polvorosa o Piñero, quemaron la casa del concejo, que en caso necesario era utilizada como prisión. En otros lugares, las consecuencias de la guerra se habían dejado sentir, más que en las propias instalaciones, en los utensilios carcelarios. La justicia de Prioro, en Léon, decía carecer de prisiones "por habérseles llevado la tropa en la pasada guerra"; en Pola de Gordón, la Almendra o Maderal, se especificaba que los franceses habían fundido los grillos y las cadenas para hacer herraduras para sus caballos; en Entrala, quemaron el cepo, único instrumento que poseía la localidad para custodiar a los presos. Estos ejemplos nos muestran el notable quebranto que la guerra causó en las instalaciones carcelarias, circunstancia que hemos de tener presente a la hora de valorar las respuestas.

\footnotetext{
${ }^{16}$ Así, por ejemplo, en la provincia de Zamora no se encuentran los territorios que estaban bajo la jurisdicción del conde de Benavente — Sanabria, Tábara y el propio Benavente — o, en la de León, Mansilla de las Mulas. Por el contrario, en una y otra aparecen localidades que tras la reforma pasaron a formar parte de otras provincias.
} 
Pero no sólo los conflictos bélicos fueron los detonantes del lamentable estado de las instalaciones carcelarias ${ }^{17}$, también contribuyeron las coyunturas económicas, demográficas u otros vaivenes políticos. En lo que respecta a esto último, en algunas localidades, prácticamente todas ellas ubicadas en la provincia de León, y más concretamente en los territorios que habían sido del señorío del conde de Luna, se recogieron en el informe las cárceles señoriales, pues no había otras ${ }^{18}$. Todas ellas estaban en situación de abandono, y es que hemos de tener en cuenta que la elaboración de la encuesta coincidió con un momento en el que la nobleza estaba perdiendo derechos jurisdiccionales en beneficio de la Corona ${ }^{19}$. A su vez, tanto en León como en Zamora $^{20}$, las últimas décadas del siglo XVIII y los primeros años del XIX había sido

\footnotetext{
${ }^{17}$ Aunque el contexto histórico en que se llevó a cabo el informe fue determinante, parece que ese estado precariedad de las instalaciones carcelarias se padeció durante épocas precedentes. Esa circunstancia era consecuencia de la pasividad de los poderes públicos. J. Serna Alonso, Presos y pobres en la España ..., p. 29.
}

${ }^{18}$ En esos territorios el abandono y estado de ruina de las cárceles lo relacionaban con la abolición del señorío, pues, hasta entonces, el mantenimiento de los edificios había sido competencia del señor. En el concejo de Omaña respondieron: "que en este citado concejo, a consecuencia de haber sido señor jurisdiccional el Excmo. Sr. Conde de Luna y corresponderle como a tal el nombramiento de alcalde mayor, escribanos y alcaide de cárcel, cuia elección está reservada hoy a la real cámara; aquel tenía destinado para cárcel de esta jurisdicción una casa castillo que llaman de Venal de su pertenencia, en donde residía el alcalde mayor y alcaide de cárcel, quedando desocupada una oficina que servía de calabozo para los reos, estando de quenta de dicho Sr. conde los reparos mayores y menores de dicho castillo como también la dotación del alcaide; mas como en el día están suspensas las regalías de los señores jurisdiccionales y el castillo es propio del dicho Excmo. Sr. conde, este concejo está hoy sin cárcel alguna". Por su parte, el también concejo leonés de Laciana, afirmaba que el estado de la cárcel había sufrido un serio deterioro tras perder la jurisdicción el conde de Luna, que era quien hasta entonces se encargaba, entre otras actividades, de llevar a cabo las obras de reparación que fueran necesarias en la cárcel. En la misma línea estaban las respuestas de las localidades de Boca de Huérgano, Almaraz de Duero o de la jurisdicción de Boñar. En esta última, las personas que respondieron a la encuesta señalaban: "en esta villa había dos cárceles, que pertenecían a los Excmos. Sres. Duque de Frías y conde de Altamira pero como se suprimieron los derechos jurisdiccionales que tenían, redujeron dichas cárceles a habitaciones, pero el corregidor luego que entró en el desempeño de su destino, que fue en diciembre último, viendo la necesidad de que en este partido hubiese cárceles, porque de continuo hay reos en ellos, como sucede en la actualidad, que se hallan dos por una muerte y uno por robos, suplicó al cura párroco que se sirviese facilitarle una panera propia de la iglesia que sirviera para custodia de los delincuentes, a lo que condescendió y sirve de cárcel”. A.CH.V., Causas Secretas, Caja 45.002 y 46.003.

${ }^{19}$ Tras la abolición de los señoríos, por parte de las Cortes de Cádiz, y la política ambigua desarrollada más tarde por Fernando VII, se generó un estado de cierta confusión. Á. García Sanz, Desarrollo y crisis del Antiguo Régimen en Castilla la Vieja. Economía y sociedad en tierras de Segovia de 1500 a 1814 , Madrid, 1977, p. 319; F. J. Hernández Montalbán, La abolición de los señorios en España (1811-1837), Madrid, 1999, pp. 185 y ss.

${ }^{20}$ Para Zamora, vid. A. Álvarez Vázquez, "La agricultura de Zamora en la época moderna”, Historia de Zamora. T. II La Edad Moderna, Zamora, 1995, pp. 113-145 y J.C. Rueda Fernández, J.F. Fernández Vecilla y E. Velasco Merino, "La población zamorana, siglos XVI-XIX”, Historia de Zamora. T. II La Edad Moderna, Zamora, 1995, pp. 249-341. Para León, L.M. Rubio Pérez,(coord.), Historia de León, León, 1999. 
nefastos en el terreno agrícola y en el campo demográfico. A lo largo de esa etapa se habían sucedido malas cosechas y graves epidemias, con el corolario de una guerra.

Finalmente, en la valoración de la infraestructura carcelaria se ha de tener presente que los datos que refleja el informe, no sólo estaban mediatizados por la situación política del momento, sino que en algunos aspectos fue determinante la subjetividad a la que se prestaban algunas cuestiones. De hecho, resulta complicado discernir cuál fue el rasero empleado para considerar a una prisión salubre o segura. Por ejemplo, las autoridades sayagesas de Bermillo y Tamame o las del concejo de Laciana afirmaban que su cárcel era segura, para matizar a continuación, que no ofrecería ninguna garantía en caso de tener que albergar a presos que hubieran cometido delitos graves "de pena capital o facinerosos", decían los lacianiegos.

\section{La red carcelaria en las provincias de León y Zamora}

A la encuesta que realizó la Chancillería de Valladolid, a comienzos del siglo XIX, para valorar la situación real de la red carcelaria, respondieron un total de 510 localidades de las provincias de León y Zamora ${ }^{21}$, concretamente 374 de la primera y 136

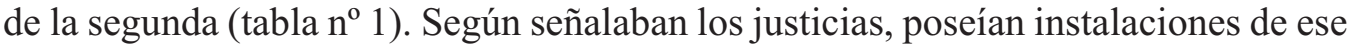
tipo solamente 210 poblaciones, es decir el $41,2 \%$ de las que contestaron. De estas, 101 pertenecían al territorio leonés y 109 al zamorano. Así pues, si nos ceñimos a los datos, mientras que en León solamente había cárcel en una de cada cuatro localidades, en Zamora, prácticamente, ocurría lo contrario. Ahora bien, esos datos cuantitativos, como ocurrirá con los cualitativos, deben de ser precisados. Pues si gran parte de los justicias de las localidades leonesas, independientemente de si tenían o no instalaciones de ese tipo, enviaron el cuestionario cumplimentado, los zamoranos eligieron otra vía para atender a esa obligación. En aquellos lugares en los que no había ningún edificio destinado específicamente a cumplir la función de cárcel, los representantes locales consideraron que no era necesario responder por escrito a la encuesta, por lo que se limitaron a trasladar verbalmente la situación al corregidor, que así lo señaló en la valoración global de su circunscripción.

\begin{tabular}{llccccc} 
& \multicolumn{3}{c}{ Tabla no $^{0}$} & 1. La red carcelaria en León y Zamora (1817) \\
& León & \multicolumn{3}{c}{ Zamora } & \multicolumn{3}{c}{ TOTAL } \\
& $\mathrm{n}^{\mathbf{0}}$ & $\%$ & $\mathrm{n}^{\mathbf{0}}$ & $\%$ & $\mathrm{n}^{\mathbf{0}}$ & $\%$ \\
Tienen cárcel & 101 & 27 & 109 & 80,1 & 210 & 41,2 \\
Carecen de cárcel & 273 & 73 & 27 & 19,9 & 300 & 58,8 \\
TOTAL & 374 & 100 & 136 & 100 & 510 & 100
\end{tabular}

Fuente: A.CH.V., Causas Secretas, Cajas 45.002 y 46.0003.

${ }^{21}$ Como hemos señalado en una nota precedente, en este expediente se recogió también la provincia de Toro. 
En lo que se refiere a las apreciaciones que debemos de realizar al contenido de esa respuesta, hemos de comenzar señalando que el propio término cárcel fue utilizado de forma un tanto subjetiva. Por ese motivo, en las contestaciones dadas a aquella pregunta del cuestionario nos encontramos con situaciones verdaderamente contradictorias, fundamentalmente en la provincia Zamorana. Así, por ejemplo, en la localidad de Fontanillas de Castro decían que no tenían cárcel y que cuando era necesario custodiar a un preso "se pone en la casa del concejo hasta que se remite a San Cebrián". Una respuesta prácticamente idéntica la dieron en Moralina ${ }^{22}$, Benejiles o Aspariegos del Pan. Esa solución, que debía de ser muy frecuente, según señalaba el corregidor, fue el motivo por el que unas cuantas localidades consideraron que no era necesario responder por escrito a la averiguación. Pero, a su vez, la gran mayoría de las que manifestaron poseer cárcel resulta que estaba ubicada en la casa del concejo, sin que dentro de ella tuviera un espacio habilitado específicamente para cumplir aquella función. Por lo tanto, ante situaciones que parecen ser idénticas, la valoración de los justicias fue diferente. En algunos casos hemos podido comprobar que poseer cepo o grillos era el matiz que inclinaba el sentido de la respuesta, pero este criterio tampoco parece resultar del todo concluyente. Por ejemplo, ni Muelas ni Montamarta declaraban ningún tipo de prisiones para asegurar a los detenidos, pero sí señalaban tener cárcel. Por el contrario, Benegiles, Aspariegos o Villalube, a pesar de poseer cepo y grillos en la casa del concejo, respondían que no tenían cárcel.

Entre las localidades que dicen disponer de instalaciones carcelarias hemos de diferenciar, al menos, tres grupos. Esa clasificación jerárquica responde a la importancia de las mismas, que derivaba del tipo de población en la que se ubicaban pero, sobre todo, de las necesidades que tenían que cubrir. En un primer nivel estarían las de ámbito urbano, que serían las más importantes, las que teóricamente gozaban de mayor seguridad y el destino de todos aquellos que habían cometido delitos considerados de gravedad. Se trataría de las cárceles de León, Zamora, Astorga o Toro. En un segundo grupo podemos incluir las localizadas en villas y núcleos de población que ejercían como cabeza de concejo mayor, jurisdicción o hermandad, y que, como tales, desempeñaban funciones administrativas. Algunas tuvieron un cometido que, hasta cierto punto, puede compararse con el desempeñado por las de la primera categoría. Se trataba de aquellas que se localizaban en poblaciones que eran final de etapa y que, por lo tanto, tenían que albergar las cuerdas de vagos o delincuentes en tránsito. Finalmente, el tercer bloque, que era, sin duda, el que mayor peso cuantitativo tuvo, estaba formado por las que se encontraban diseminadas por las pequeñas localidades del mundo rural, casi todas situadas en pequeños edificios de uso versátil.

\footnotetext{
${ }^{22}$ Concretamente, dicen que utilizan, cuando era necesario, la casa del concejo "en la que vive el tabernero y en la que hay un cepo con su candado y llave correspondiente, en la que se asegura a los reos cuando los hay, pero como este pueblo está sujeto a Zamora, y sus alcaldes no ejercen jurisdicción ordinaria, luego que se verifica la prisión de algún reo se da inmediatamente parte al alcalde mayor de dicha ciudad, aunque da orden para que se conduzca a la cárcel real de ella”. A.CH.V., Causas Secretas, Caja 46.003.
} 


\section{a) Las cárceles urbanas}

En las provincias de León y Zamora había cuatro cárceles de este tipo: León y Astorga, en la primera, y Zamora y Toro en la segunda. La cárcel de mayor tamaño, y también la más moderna, era la de la capital zamorana. Su construcción se había iniciado a finales de la década de los ochenta del siglo XVIII. Las instalaciones, incluidos patios y corrales, ocupaban unos 2.800 metros cuadrados, casi tres veces más que la de la capital leonesa, que apenas superaba los 1.000. Más pequeñas eran las de Toro, que disponía de 552, y Astorga. El tamaño de ésta es difícil precisar, pues el recinto donde se albergaba tenía varios usos, pero en cualquier manera era el edificio con el perímetro más reducido.

Esas cárceles, que eran consideradas como las más seguras, servían de referencia para cada una de las demarcaciones de esos núcleos urbanos. Pero la realidad era otra, puesto que las inspecciones realizadas por las autoridades políticas y los técnicos, a propósito de la encuesta, ponían en evidencia la precariedad de las infraestructuras, poco acordes al fin al que estaban destinadas. En cada una de ellas, en mayor o menor medida, se manifestaba la necesidad de acometer profundas reformas, para mejorar tanto la seguridad como la salubridad ${ }^{23}$. El lamentable estado en el que se encontraba alguno de esos establecimientos carcelarios, como era el de la ciudad de León, ya se venía arrastrando desde hacía siglos y en otros era una consecuencia más de la reciente guerra.

Como ya señalamos, la cárcel de la capital zamorana era de reciente construcción ${ }^{24}$.

En 1788, coincidiendo con un momento de expansión urbanística de la ciudad, el Consejo de Castilla había expedido una Real Orden para la creación de una junta en la ciudad que debía de encargarse de la construcción de esa prisión. Para costear las obras se realizó un reparto entre los vecinos de "los pueblos de varias provincias". En su edificación se había tenido muy presente que a este establecimiento serían enviados los arrestados, de prácticamente toda la provincia, que estuvieran acusados de cometer delitos graves. De hecho, mientras que para para encerrar a éstos se reservaron 18 "mansiones", para los considerados "leves" sólo 5. La cárcel anterior, carecía de cualquier medida de seguridad y, tal y como señalaban los justicias a comienzos del siglo XVIII, si no fuera porque la ciudad empleaba soldados de la guarnición para custodiarla "desvelo alguno hubiese bastado para evitar las fugas y rompimientos"

En el momento en que se realizó el informe, 1817, las obras de la cárcel no habían finalizado del todo y parte de las que ya se habían efectuado presentaban un avanzado

\footnotetext{
${ }^{23}$ En las cárceles de la época, la falta de seguridad y de unas condiciones higiénicas adecuadas eran un mal muy generalizado. Para Portugal puede consultarse M.A. Lopes, Pobreza, Asistencia e Controlo Social. Coimbra (1750-1850), Viseu, 2000, pp. 525 y ss.

${ }^{24}$ En la segunda mitad del siglo XVIII la provincia de Zamora disfrutó de una fase de esplendor urbano, si bien ese se cimentó sobre la base de unas estructuras económicas poco, o nada, innovadoras. A. Álvarez Vázquez, "La agricultura de Zamora..., pp. 113-145

${ }^{25}$ A.H.N. L. 12.483-3.
} 
estado de deterioro. La Guerra y el uso de materiales poco adecuados para dar solidez al edificio serían los causantes de aquella situación, difícil de subsanar. A comienzos del siglo XIX, y a causa de la falta de caudales en el fondo de propios, el regimiento de la ciudad paralizó todos los trabajos, ya se tratara de proyectos de reparación o de pequeñas nuevas construcciones. La única vía para retomar la obra era repartir los gastos que ocasionara entre los vecinos de la ciudad y pueblos del entorno. Entre las intervenciones que debían de llevarse a cabo, el maestro de obras señalaba, como prioritaria, acondicionar el piso principal, que estaba totalmente diáfano, y en el que, según el proyecto original, debían de ubicarse diversas oficinas y la vivienda del alcaide. El coste de esos trabajos lo tenían presupuestado en unos 40.000 reales. Una cantidad menor - que según calculaba el técnico ascendería a unos 10.520 realesera la que necesitaban para reparar el tejado y cambiar las puertas de doce calabozos, que estaban totalmente apolilladas. Así pues, y a pesar de tratarse de un edificio relativamente reciente, las deficiencias estructurales que padecía eran considerables, más graves aún si tenemos en cuenta su cometido.

Por otro lado, y aunque el corregidor de Zamora no hizo referencia a ella en la encuesta realizada por la Chancillería, en esa ciudad existía también una galera, o cárcel de mujeres. Se había puesto en funcionamiento, bajo supervisión eclesiástica, en 1767. A partir de 1774, las mujeres que cumplían condena en ella, se "corregían" trabajando en una fábrica textil ${ }^{26}$. En la última década del siglo XVIII las reclusas fueron trasladadas al Hospicio, donde se les habilitó una sala aislada del resto de las dependencias ${ }^{27}$.

En la provincia de León la cárcel más importante era el de la capital, donde se recluían no sólo "los criminales de la ciudad, sino también de los pueblos de su jurisdicción ordinaria y de los juzgados del corregimiento, intendencia y adelantamiento de este reino y para custodiar a los que remiten a ella por segura las justicias ordinarias de toda la provincia" 28 . A comienzos del siglo XIX la cárcel leonesa, a pesar se hallarse en un estado lastimoso ${ }^{29} \mathrm{y}$ de todas las deficiencias estructurales, era tenida por "cárcel segura". Estaba situada en las antiguas caballerizas del viejo palacio real - construido a finales del siglo XIV—, que había sido cedido por Carlos V, en 1528, para ser utilizado como residencia del corregidor y cárcel de la ciudad y del adelantamiento ${ }^{30}$.

\footnotetext{
${ }^{26}$ A. Martín Márquez, "La Casa Galera y fábrica de paños de Zamora: ejemplo de beneficencia eclesiástica en el siglo XVIII", Anuario del Instituto de Estudios Zamoranos "Florián Ocampo", 11, 1994, pp. 481-508.

${ }^{27}$ M.I. Galicia Pinto, La Real Casa Hospicio de Zamora. Asistencia social a marginados (1798-1850), Zamora, 1985; A. Martín Márquez, "La casa galera y fábrica de paños de Zamora..., pp. 481-508

${ }^{28}$ A.M.L., Actas Municipales, Caja 79.

${ }^{29}$ También la ruina y falta de espacio fue un problema que tuvo que solucionar la cárcel de Pamplona, entre otras, en el siglo XVIII. P. Oliver Olmo, Cárcel y sociedad represora. La criminalización del desorden en Navarra (siglos XVI-XIX), Bilbao, 2001, pp. 95 y ss.

${ }^{30}$ M.I. Viforcos Marinas, El Adelantamiento del reino de León en el siglo XVII, Memoria de Licenciatura, 1982, pp. 160-161. Durante unos años continuaron funcionando ambas cárceles. M.D. Campos Sánchez-Bordona y J. Pérez Gil, El Palacio Real de León, León, 2006, pp. 141 y ss.
} 
Desde la puesta en funcionamiento de estas instalaciones, los regidores denunciaron que no eran adecuadas para albergar presos, ni por el tamaño del edificio ni por su ubicación. Poco después de la cesión se llevaron a cabo obras de remodelación en el edificio, pero fueron muy elementales, sin la solidez que requieren este tipo de establecimientos. Esa precariedad fue arrastrándose a lo largo de toda la Edad Moderna, y, de hecho, en la segunda mitad del siglo XVIII el estado de la cárcel era lastimoso, a pesar de las continuas intervenciones que se habían realizado poco tiempo antes. De hecho, en $1752^{31}$, 1754 o 1761 el alcaide comunicaba al regimiento que el edificio ${ }^{32}$ amenazaba ruina. Pese a las diferentes obras acometidas esos años y las que continuaron realizándose, los problemas de base no pudieron solventarse por lo que, entre otras cosas, tampoco se resolvió el tema de la seguridad, como demuestran las reiteradas quejas de los alcaides a lo largo de esos años y los sucesivos intentos de fuga ${ }^{33}$.

En un informe realizado en 1801 por el alcalde mayor de León, a petición fiscal del crimen de la Chancillería de Valladolid, se repetían las constantes quejas lanzadas a lo largo de los siglos precedentes. El magistrado reconocía la falta de seguridad de la cárcel "por ser de fábrica muy antigua con algunas paredes de tierra", así como lo reducido de sus dimensiones "para los muchos presos que a ella se destinan"34. Precisamente, el requerimiento para que se elaborara ese documento era consecuencia de la más espectacular de las fugas acontecidas hasta entonces ${ }^{35}$. El 26 de marzo de aquel año se habían escapado de la prisión un total de veintiséis reos ${ }^{36}$. Ese perma-

\begin{abstract}
${ }^{31}$ En 1754, se recogía en las Actas Municipales de la ciudad: "viose un pedimento de Alonso Álvarez, alcaide de la Real Cárcel de esta ciudad, en que expone que las paredes del patio corral de dicha cárcel con las aguas, nieves y aires se hallan destejadas y menoscabadas por lo que si no se da pronta providencia para su refacción se vendrá a tierra, como también la del cubo y común de dicha cárcel por cuyos motivos no poder asegurar preso alguno suplicando que con la mayor brevedad se mande reparar para seguridad de los presos" A.H.M.L., Actas municipales, Caja 75.
\end{abstract}

${ }^{32}$ A.H.M.L., Actas municipales, Caja 74.

${ }^{33}$ Los de finales del siglo XVIII estuvieron protagonizados por unos presos que veían prolongarse el encierro, a causa de la lentitud con la que se desarrollaban sus procesos judiciales. La falta de seguridad del edificio facilitó el que algunas de esas tentativas de evasión tuvieran con éxito. En 1795 se fugaron dos presos y, a pesar de que en el auto de buen gobierno que fue elaborado al año siguiente se puso especial énfasis en lo referente a la seguridad, en 1799 otros dos reclusos lograron escaparse, rompiendo el endeble techo del calabozo y neutralizando al alcaide. Poco después, en enero de 1800, de nuevo, dos presos lograron traspasar los muros carcelarios. En este caso la huida se produjo tras descerrajar dos candados y descender por la ventana de la sala de audiencias, ayudándose de las sábanas de la enfermería. A.H.M.L., Actas municipales, Cajas 78, 94 y 95.

${ }^{34}$ A.CH.V., Pleitos criminales, Caja 1.641-4.

${ }^{35}$ No obstante, y a pesar de que el estado de las instalaciones era totalmente inadecuado para la misión que cumplían, parece que en esta fuga tuvo mucho que ver la falta de profesionalidad del alcaide. De hecho, tres años después de esos acontecimientos, el tribunal le ordenaba, como también al resto del personal de la cárcel, que "en manera alguna se mezclen con los presos en comilonas ni otros convites ni les permitan tanta libertad que proporcione su fuga". A.CH.V., Pleitos criminales, Caja 1.641-4.

${ }^{36}$ Esos presos para intentar exculpar su delito alegaron, ante el tribunal que trataba de esclarecer las causas de la fuga, la miseria en que vivían, el exceso de trabajo, el maltrato espiritual y corporal que re- 
nente estado de ruina de las instalaciones carcelarias motivó que, a comienzos del siglo XIX, el regimiento leonés aprobara un ambicioso proyecto: trasladar la cárcel desde el viejo palacio real al torreón de puerta castillo, el cual ya había cumplido esa función en siglos precedentes. El 13 de enero de 1801 ordenaban al arquitecto municipal que elaborara los informes y planos pertinentes para convertir el torreón en "una cárcel segura". Sin embargo, las dificultades políticas del momento frenaron los planes y hasta 1878 no se abandonó el viejo palacio real.

Respecto a la ciudad de Toro, los justicias consideraron que la cárcel podía considerarse segura, pero también señalaban que, a pesar de las apreciables dimensiones de la misma, no tenía plazas suficiente para satisfacer la demanda. Esa falta de capacidad se convirtió en un problema difícil de solucionar, puesto que no era sencillo ampliar el espacio construido, debido a que lindaba por dos costados con otros edificios, concretamente con casas particulares y las escuelas, y con calles públicas por los otros. Por otro lado, y a pesar de la seguridad a la que hacían referencia en el informe, se trataba de un inmueble antiguo que ya se hallaba bastante deteriorado, a lo que también habían contribuido los franceses ${ }^{37}$. El maestro de obras informaba, entre otras deficiencias, que todos los muros del edificio eran "muy débiles", lo mismo que las maderas del suelo, que además estaban corridas. Esa precariedad había alentado varios intentos de fuga, a raíz de los cuales ya se había subsanado algunas deficiencias, como reforzar algunas paredes con piedra y ladrillo.

Finalmente, los encargados de elaborar el informe en la capital maragata nos ofrecieron abundante información. En Astorga, la cárcel y el Ayuntamiento compartían edificio. Al primer uso destinaban una serie de salas que se repartían por tres plantas. En la baja estaba el calabozo, semisubterráneo, que tenía una ventana enrejada que daba a la calle; en el piso siguiente había de tres celdas y el cuarto y cocina del alcaide "bastante suficiente para este fin". Finalmente, en la última planta había un oratorio - "con todo lo necesario para celebrar, con una ventana y su reja para que los presos de los calabozos puedan ver la misa"-, una cocina, para el servicio de los presos de distinción, una celda, donde eran custodiados, y una pieza llamada "de audiencia", posiblemente porque en ella se celebraban los juicios. En esta última estancia, o incluso en las casas consistoriales, también podían recluir a "los nobles y personas condecoradas". Para una ciudad del tamaño de Astorga esas instalaciones carcelarias poseían una notable capacidad de albergue, lo que respondería, más que a ser cabeza de partido, a su posición estratégica en la ruta viaria de la época. Era fin de etapa para

cibían y la lentitud de sus procesos. La mayor parte de ellos ya habían sido juzgados y condenados a servir en el arsenal del Ferrol o a galeras, pero, a causa de otros intentos de fuga que anteriormente habían protagonizado, sus condenas se hallaban paralizadas. Pedían, sin exonerarse de esos delitos, ser enviados a sus destinos, para poder ir redimiendo las penas que sobre ellos recaían. Atendiendo a estas justas quejas, la Chancillería ordenó que el corregidor enviase inmediatamente a los presos a cumplir sus condenas. A.CH.V., Pleitos criminales, Caja 1.641-4.

${ }^{37}$ Entre otros desperfectos habían inhabilitado la sala de visitas. A.CH.V. Causas Secretas, Caja 46.3. 
las cuerdas de vagos y delincuentes que las justicias ordinaria y castrense desplazaban entre el reino de Galicia, fundamentalmente, y la Meseta ${ }^{38}$.

Respecto a la seguridad de las instalaciones, mientras el calabozo era considerado por las autoridades de la ciudad como la estancia más segura, con las celdas no sucedía lo mismo. Entre las deficiencias que registró 1817 el maestro de obras que se encargó de inspeccionar el edificio, Lázaro Lorenzo, se señalaban como de actuación prioritaria el colocar un techo raso, para cubrir las vigas ${ }^{39}$, y reforzar las paredes con masilla o mezcla de cal, para evitar que los presos escarbaran entre las piedras e hicieran agujeros por los que fugarse, como ya había sucedido en alguna ocasión. Gran parte del calamitoso estado que sufría la cárcel maragata por esas fechas, era, como en otros lugares, consecuencia de la ofensiva de las tropas napoleónicas que, entre otros desmanes, habían quemado las contras de las ventanas y robado los herrajes ${ }^{40}$. No obstante, y como ocurría en la capital leonesa, estamos ante un deterioro que ya hacía años que se venía arrastrando ${ }^{41}$. Todas estas deficiencias también acabaron por propiciar la búsqueda de una solución sobre la base de un ambicioso plan de reforma. Para ello proyectaban ampliar las instalaciones utilizando las casas contiguas, pero también en este caso las obras tuvieron que esperar.

Como acabamos de ver, las cárceles urbanas de las provincias de León o Zamora eran modelos constructivos que nada tenían que ver con el patrón de arquitectura carcelaria que surgió en Europa a finales de la centuria dieciochesca y principios de la siguiente ${ }^{42}$. A nivel general, y a tenor de toda la información proporcionada por la encuesta de 1817, en esas cárceles se constatan dos graves deficiencias: falta de espacio y precariedad de los inmuebles. Incluso en las más importantes era difícil disponer de salas suficientes para separar a los presos en función del sexo o gravedad del delito $^{43}$. Cuestión por la que habían abogado Sandoval o Cerdán de Tallada hacía más

\footnotetext{
${ }^{38}$ A. Martín García, "Levas honradas y levas de maleantes: los trabajadores forzosos en un arsenal del Antiguo Régimen”, Obradorio de Historia Moderna, 8, 1999, pp. 231-260, p. 248.

${ }^{39}$ Concretamente, consideraban que para evitar los peligros de fuga por el tejado era necesario "asegurar el armazón de los tejados, pues como están descubiertas cuelgan sogas o cordeles y por ellos descubren las tablas y tejas de dicho armazón y se fugan los presos como ya se ha verificado". A.CH.V., Pleitos criminales, Caja 1.641-4.

${ }^{40}$ Sobre los dos sitios que sufrió la ciudad de Astorga, Vid. A. García Fuertes, El Grito de una Nación. Dos de mayo de 1808, Barcelona, 2008.

${ }^{41}$ Ese estado de ruina de la cárcel astorgana, se hacía evidente casi un siglo antes de elaborarse ese informe. En 1737, el corregidor de Astorga ordenaba a los Cuartos de la ciudad que contribuyeran a la reedificación de la cárcel y que participaran en los turnos de vigilancia. La orden dio lugar a un pleito que perdió el Corregidor, puesto que el alfoz y los Cuartos se amparaban en una sentencia ganada en 1603, según la cual el coste que generara el mantenimiento de la cárcel debía de ser afrontado por la ciudad. A.CH.V., Ejecutorias, Caja 3.180-32.

${ }^{42}$ J. E. García Melero, "Las cárceles españolas de la ilustración y su censura en la Academia (17771808)", Espacio, Tiempo y Forma, Serie VII, Historia del Arte, 8, 1995, pp. 241-272

${ }^{43}$ Estas deficiencias parece que estaban muy generalizadas. F. Tomás y Valiente, "Las cárceles y el sistema penitenciario bajo los Borbones”, Historia 16, extra VII, 1978, pp. 69-88.
} 
de dos siglos. Por ejemplo, en la ciudad de León, el auto de buen gobierno de 1796 insistía en que se cumpliera esa normativa para evitar que la promiscuidad acabara convirtiendo la cárcel en una escuela de delincuencia ${ }^{44}$. Esa limitada capacidad que mostraban los edificios, sería, en parte, consecuencia del crecimiento de la población en el siglo XVIII. Prácticamente, todas las cárceles, salvo la de Zamora, se habían quedado obsoletas, por no haber sido adaptadas a las nuevas necesidades, bien porque carecían de espacio que pudiera ser utilizado para agrandar las construcción, o, cuando lo tenían, porque la falta de fondos había obstaculizado la remodelación.

A su vez, mayoritariamente, y como luego se repetirá en casi todas las villas, cada uno de esos conjuntos arquitectónicos respondía al modelo constructivo diseñado por los Reyes Católicos en los albores de la Edad Moderna. Dichos monarcas, habían establecido que la cárcel, la audiencia y las dependencias del carcelero debían de alojarse en el mismo edificio ${ }^{45}$. El objeto de esa multifuncionalidad era proyectar todas las facetas del poder: legislar dentro de su ámbito competencial, velar por el cumplimiento de las normativas y la legítima capacidad de represión sobre aquellos que las infringían. Esa misma idea se halla presente en la decisión de Carlos V, a comienzos del siglo XVI, de albergar en el palacio real que donó a la ciudad de León, la casa del corregidor, la audiencia y la cárcel.

\section{b) Las cárceles de las villas}

En este grupo podemos incluir las cárceles de un número relativamente importante de localidades, que, en muchos casos, actuarían como depósitos de los prisioneros de su jurisdicción y, también, de los del entorno rural más próximo. Pues los justicias de estos últimos territorios, cuando se veían obligados a custodiar a un reo de aparente peligrosidad, ante la falta de un centro donde alojarlo, solían llevarlo a las cárceles de esas villas, que, en teoría, eran más seguras. Pero la gran mayoría eran inmuebles que ofrecían muy pocas garantías de seguridad, al menos en ese momento. Algunas de las cárceles que podemos englobar en este grupo fueron muy bien descritas por sus responsables. Es el caso de las de Ponferrada, Valderas, Peñausende, Alaejos o Alcañices. Como les ocurría a las urbanas, también en éstas quedaron reflejados los descalabros sufridos durante el conflicto bélico contra los franceses.

Comenzando por las zamoranas de Peñausende y Alaejos, su importancia radicaba en que ambas localidades eran fin de etapa de las cuerdas de presos. En la primera paraban los que desplazaban entre Zamora y Ciudad Rodrigo; y por la segunda cru-

\footnotetext{
${ }^{44}$ En uno de los capítulos se ordenaba que el Alguacil "será muy escrupuloso a la hora de separar hombres de mujeres, presos por deudas de aquellos otros que hubieran cometido delitos infames; personas de clase o estimación con facinerosos y bandidos; párvulos y jóvenes con delincuentes envejecidos". Para la Corona de Castilla, sobre estas cuestiones Vid. M.P. Alonso Romero, El proceso penal en Castilla: siglo[s] XIII-XVIII, Salamanca, 1982, pp. 324-325.

${ }^{45}$ Novísima Recopilación, Lib. XII, T. 38, L. 2.
} 
zaban las calzadas que unían Madrid con Zamora y Valladolid con Salamanca y Ciudad Rodrigo. La cárcel de Peñausende formaba parte de un conjunto de instalaciones que poseía la casa del concejo, que era de apreciables dimensiones, pues ocupaba unos 300 metros cuadrados. En la planta alta se ubicaba la sala del ayuntamiento y en la baja los calabozos, las dependencias del carcelero y una sala para las carnicerías. Esta última tenía una entrada independiente. El edificio estaba precedido por un portal alargado, donde se reunían y deliberaban los representantes de la localidad; a continuación, había una pequeña estancia, de la que partía una escalera que daba acceso al piso superior. A ambos lados de aquella, se situaban los calabozos, que, como en otras cárceles, en ese momento "se hallan muy deteriorados, que así los dejaron las tropas enemigas". Realizar las reparaciones necesarias en esta cárcel podría costar, según estimaban los justicias, entre 9.000 y 10.000 reales, dinero del que en ese momento no disponían. Por su parte, la de Alaejos constaba de tres piezas, un calabozo seguro, adyacente a un portal, en el que había capacidad para encerrar a 10 hombres; otra pieza, que daba a la plaza, con menos seguridad, en la que se podían alojar hasta 12 presos; y la tercera, en el piso superior, que llamaban la de "los presentados".

De gran importancia fue también la de Alcañices, debido a que era la única que poseía la villa y los 53 pueblos del partido de Aliste. A esa circunstancia se añadía su proximidad con la frontera de Portugal ${ }^{46}$. En aquel momento, la cárcel estaba casi en un estado de ruina, no sólo por los graves destrozos causados por los franceses, que aún no se habían reparado, sino también por el deterioro que venía arrastrando. Tenía dos piezas "una que se llama reja y otra calabozo", ambas de pequeñas dimensiones y comunicadas entre sí. A la primera estancia se accedía directamente desde la calle y de ella se pasaba al calabozo. El alcaide tenía un pequeña habitación, que, cuando era necesario, se utilizaba para encerrar a las mujeres "sin ninguna seguridad".

Respecto a las leonesas, la de Ponferrada había sido construida en la década de los setenta del siglo XVI y antes de la guerra también venía arrastrando un estado de visible precariedad, lo que llevó a D. Francisco Egea y Corbalán, corregidor de la villa, a iniciar, a comienzos del siglo XIX, las obras de un nuevo edificio. El fallecimiento del magistrado y las dificultades de la guerra paralizaron el proyecto ${ }^{47}$. En consecuencia, en 1817 la cárcel de la villa y su partido "consiste en el día en una panera de las del pósito a quien la necesidad ha precisado a darle este destino"48. Por su parte, el edificio de la cárcel de la villa de Valderas constaba de dos pisos, y no era

\footnotetext{
46 "Esta villa ... siendo intendencia a la raya de Portugal, cuyo reino solo dista una pequeña media legua de esta villa, hay precisión de recibir los reos que salen de la provincia de Tras-os-Montes, del mismo Portugal para España y entregar los que de este Reino hayan de entrar para aquel por la misma provincia, pues Alcañices y su partido confinan con los territorios y jurisdicción de las capitales portuguesas denominadas Bragança, Vimioso, Miranda do Douro y de consiguiente en muy pocas épocas deja de haber 4-6-8 o más presos". A.CH.V., Causas Secretas, Caja 46.0003.

${ }^{47}$ F. González González, Cárceles ponferradinas. Horcas, rollos y picotas, Ponferrada, 1997, pp. 63-74. ${ }^{48}$ A.C.H.V., Pleitos criminales, Caja 1.641-4.
} 
de los más arruinados a comienzos del siglo XIX. En la planta baja se hallaba el calabozo, con capacidad para acoger a unos quince reos, que se usaba para custodiar a los recluidos por delitos graves. Este espacio, según los informadores, no era seguro, porque las paredes eran de tierra, por lo que proponían la conveniencia de sustituirlas por otras de cantería. Contiguo al calabozo existía un oratorio, al que seguía un corral. En la parte alta había dos estancias: la vivienda del carcelero, compuesta por un "recibimiento", una sala y una cocina, y un cuarto que se usaba para los presos acusados de delitos menores.

A nivel general, los informes parecen mostrar que las cárceles de las villas eran un reflejo, a menor escala, de las que tenían las ciudades. No todas tenían la misma importancia, pues esa derivaba de la localización geográfica de la localidad o de su radio de influencia. En las que hemos presentado, todas con responsabilidades importantes, quedó reflejado el deterioro de las instalaciones carcelarias que poseían, pero, como en el caso anterior, ese no fue sólo consecuencia de la guerra, sino que ésta sólo contribuyó a agravarlo. Los edificios carcelarios poseían entre dos y tres salas para custodiar a los presos, que solían estar repartidas en dos pisos ${ }^{49}, \mathrm{y}$, en un gran número de localidades, no se trataba de inmuebles independientes, con un cometido específico, sino que formaban parte del Ayuntamiento o casa del concejo.

\section{c) Las cárceles del mundo rural}

En este ámbito, pocos fueron los edificios que tuvieron un uso exclusivamente carcelario, salvo en las poblaciones que ejercían como cabeza de una unidad administrativa, caso de concejos o hermandades. Sólo en el partido del Bierzo fueron mayoritarias las localidades que decían poseer un establecimiento dedicado específicamente a prisión, pero la parquedad con la que en esa demarcación respondieron al cuestionario nos obliga a tomar el dato con cierta precaución.

En localidades con cierta entidad se repetía el esquema de las villas, por lo que lo más habitual era que el edificio del ayuntamiento o la casa del concejo tuvieran dos plantas, una se utilizaba para encerrar a los delincuentes y la otra como sala de audiencias. Pero en la gran mayoría de los pequeños pueblos la casa del concejo tenía una sola pieza o, a lo sumo, dos, a las que daban un uso versátil, entre los que estaba

\footnotetext{
${ }^{49}$ Por ejemplo, en la villa de Cacabelos, en la planta baja del edificio se situaba la cárcel y en la alta la sala de plenos y residencia del alguacil, que realizaba las funciones de carcelero. Por su parte, en Vega de Espinareda, en el piso inferior se hallaba la celda para los reos de gravedad y en el superior las oficinas del ayuntamiento, así como otras salas para custodiar a mujeres y detenidos de distinción. A.CH.V., Causas Secretas, Caja 45.0002. En prácticamente todas las localidades bercianas esos edificios necesitaban ser construidos, puesto que habían quedado "arruinados" a consecuencia de la Guerra de la Independencia. Por ejemplo, los planos de la nueva cárcel de la villa de Bembibre, elaborados por Sánchez Pertejo, fueron aprobados por la Real Academia de San Fernando en 1828. E. García Melero, "Las cárceles españolas de la ilustración y su censura en la Academia..., p. 269.
} 
el adecuarlas, cuando era preciso, para ser utilizadas como cárcel. Muchas veces, la adaptación simplemente consistía en colocar en la puerta a unos vecinos ${ }^{50}$ que hicieran la función de guardias o en asegurar al detenido con unas prisiones. En la localidad zamorana de Villamor de la Ladre, la cárcel estaba ubicada en la casa donde se "asiste al abasto de la taberna". Allí tenían un cepo de madera con el que inmovilizaban a los "malhechores y desobedientes". En Peleas de Abajo la misma casa era utilizada como cárcel y panera. En la demarcación de Toro solían custodiar a los apresados en la casa del guardia de campo. En la leonesa de Riaño la solución que adoptó fue habilitar una pieza en la escuela para custodiar a los presos. Algo similar ocurría en la localidad zamorana de Monfarracinos, pero en este caso la división del edificio aún no se había realizado. En Llanaves de la Reina, situada en la montaña oriental de León, cuando tenían que responsabilizarse de algún prisionero, hacía las veces de cárcel una de las dos dependencias de una casa del concejo, concretamente la que utilizaban como sala de reuniones; la otra, era establo y pajar, en la que encerraba al toro del pueblo y se guardaba el heno para el invierno.

Respecto a aquellas poblaciones que no tenían cárcel o un lugar para habilitar como tal, al menos temporalmente, lo más frecuente era que enviaran al delincuente capturado a una localidad que dispusiera de ella, y que se considerara segura. Por ejemplo, en el pueblo zamorano de Olmillos de Castro, decían que enviaban a los detenidos a la justicia ordinaria de Perilla, y en ésta declaraban que los "de consideración" eran remitidos a San Cebrián de Castro. Respecto a la forma de efectuar el traslado, en la Hermandad leonesa de la Valdoncina nos explican las dos formas que tenían de hacerlo: "de justicia en justicia o bien por tres o más vecinos de donde se coge".

Mientras se llevaba a cabo el traslado del preso o cuando ése había cometido un delito de poca consideración, como eran las infracciones a la normativa concejil, la justicia encomendaba su custodia a algún vecino, que en caso necesario era auxiliado por alguno más. Para seleccionar a la persona que debía asumir esa responsabilidad se utilizaban dos fórmulas: que corriera la obligación entre los vecinos ${ }^{51}$ por turno anual o bien cada vez que surgiera el problema. Un caso excepcional fue el de la localidad de Calzadilla de los Hermanillos, en el sureste provincia de León, donde el alguacil elegía, sin ningún tipo de directrices, salvo las que marcaba la lógica, a un vecino para que realizara las labores de custodia del preso o, en su defecto, se lo ordenaba al que se había avecindado más recientemente. Esto último era norma en Perilla de Castro, Zamora, donde ejercían como alcaides los "vecinos nuevos". Es difícil

\footnotetext{
${ }^{50}$ En Andavías (Zamora), donde decían poseer cárcel y estar ubicada en la casa del concejo, señalaban que "en caso de haber algún preso es carga de los vecinos custodiarlo hasta entregarlo en la capital". A.CH.V., Causas Secretas, Caja 46.0003.

${ }^{51}$ Por ejemplo, en la villa zamorana de Cerezal declaraban: "no ha habido cárcel pública, y si solo para la custodia de presos se elige anualmente la casa de un vecino, adonde se recogen los presos y eso lo hace cada vecino el año que le toca como gabela y carga concejil, sin sueldo alguno". A.CH.V., Causas Secretas, Caja 46.0003.
} 
precisar donde tenían encerrado al delincuente, posiblemente en la casa del concejo, pues, como hemos dicho, algunas localidades así lo señalaron después de contestar que no poseían edificio carcelario; pero en otros casos sabemos que el depósito se efectuaba en la casa de un vecino. Así lo declaraban en Lugán - -en una oficina en la casa de un vecino que por ello es exonerado de hacenderas"- - o en el Concejo de la Tercia, donde, por turno, hacía las veces de cárcel la casa de un vecino - "ha tenido y tiene por uso y costumbre, de inmemorial tiempo a esta parte, el afianzarla cada mes un pueblo la cárcel por turno"-.

Independientemente del modo en que recaía la obligación de custodia en un vecino, los responsables del concejo le entregaban, para que ejerciera el oficio con ciertas garantías, los utensilios de prisión que tuvieran, cepo, cadenas o grillos. Reiteramos, que este tipo de custodia vecinal solamente se ponía en práctica cuando se trataba de acusados por delitos leves, pues aquellos a los que se les atribuían otros de mayor entidad eran enviados, con la rapidez que fuera posible, a cárceles más seguras.

\section{La seguridad y salubridad de las cárceles}

Otras cuestiones por las que se interesaba la encuesta de 1817 fueron las condiciones de seguridad y salubridad de las cárceles. Unas cuantas localidades fueron muy claras al respecto, contestando tajantemente que no eran seguras. Así los hizo, entre otras muchas, Fermoselle, donde añadían que "se han fugado presos por roturas que han hecho en las paredes". Lo mismo sucedía en Toro, "porque todas las paredes, exteriores, interiores y medianiles son muy débiles y las maderas corridas y débiles". También las hubo que calificaron sus instalaciones de medianamente seguras, como fue el caso de Alaejos. En esa localidad, el calabozo sí que ofrecía garantías pero el resto de las dependencias se hallaban arruinadas. No obstante, fueron mayoritarias las respuestas efectuadas por las autoridades locales que resultan excesivamente subjetivas, cuando no contradictorias ${ }^{52}$. En no pocos casos, tras contestar que el edificio podía considerarse seguro, exponían la necesidad de acometer importantes obras de remodelación o, al menos, comprar el material de prisión básico para evitar las fugas. Es el caso, entre otros, de Valderrueda o Fadón. Consideraban que las instalaciones carcelarias eran seguras, sin embargo, en la primera localidad señalaban que carecían de cadenas, candados y cepos suficientes; en la otra, el tejado estaba destrozado. Por lo tanto, si nos ajustáramos exclusivamente a la primera respuesta que dieron los justicias, los resultados que pudiera arrojar una estadística sobreestimarían claramente el porcentaje de cárceles seguras.

\footnotetext{
${ }^{52}$ Es el caso, entre otros, de Vega de Espinareda donde, y a pesar de que en el interrogatorio de no se anotó nada que hiciera sospechar del mal estado de las instalaciones carcelarias, el informe realizado por el corregidor de Ponferrada, en 1817, incluía a aquella cárcel, junto a las de Villafranca del Bierzo, Borrenes y Vega de Valcarce entre las que era necesario realizar importantes reparaciones. A.CH.V., Causas Secretas, Caja 45.002.
} 
Por otro lado, también hemos de tener en cuenta que la seguridad era relativa, puesto que, casi mayoritariamente, las justicias consideraban seguras sus cárceles siempre y cuando no estuvieran destinadas al albergar presos peligrosos. Por ejemplo, en la localidad leonesa de Abelgas de Luna se mostraba satisfechos con sus instalaciones y justificaba la respuesta añadiendo que: "porque hasta el presente no ha estado en ella persona alguna de delito grave ni forajida". En Prianza sucedía lo mismo, puesto que "se pasan años sin tener presos" y en la misma línea se hallaban, en Pardamaza, Caldas de Luna, Santa Marina de Torre, prácticamente todas las de la comarca zamorana de Sayago ${ }^{53}$, San Pedro de la Nave o Jambrina, donde sólo se utilizaba "para la retención y corrección de los vecinos".

Otra cuestión muy importante en las cárceles, y fundamental para los que estaban encerrados en ellas, era el de la salubridad. En este aspecto volvemos a encontramos con el problema de la subjetividad, que marcó las respuestas que se recogen en la encuesta. Determinante en este tema sería también la densidad ocupacional, fundamental en el ámbito urbano o en aquellos lugares que por ser cabezas de partido o final de etapa debían de alojar un número importante se presos.

Resulta complicado desentrañar la verdadera dimensión del término salubre en la mentalidad de la época. A juzgar por las respuestas analizadas, parece que las cuestiones fundamentales en las que se fijaban para determinar la salubridad de una cárcel eran: la ventilación de las celdas, la humedad y la temperatura. En las localidades de Cabañas Raras, el coto de Balboa, en la abadía de Montes, Venialbo o Fermoselle, estas dos últimas en la provincia de Zamora y el resto en la de León, apuntaban a la humedad como causa principal de las malas condiciones padecidas por los presos. Esta misma circunstancia, junto a la falta de ventilación, la reflejaba, por ejemplo, Salas de los Barrios. En general, las condiciones de habitabilidad debían de ser muy precarias, y lo único que salvaba a los presos de padecer sus graves consecuencias era el poco tiempo que pasaban en ellas. Así lo señalaban en Monfarracinos, donde no llegaban a concretar la respuesta a la pregunta, y decían que no sabían si era salubre o no porque "los presos están pocos días, pues parten para la capital".

Pero tampoco las cárceles urbanas o de las villas ofrecían garantías de salubridad a los presos. De hecho, en las instalaciones de la capital leonesa las condiciones debían de ser tan precarias como la propia estructura del edificio. En 1817 se describían sus salas como poco saludables "por faltarles la ventilación y estar en situación húmeda y baja respecto al pueblo y calles que le circundan". Las mismas condiciones ofrecía la de Toro, donde las salas y los calabozos carecían de ventilación y tampoco en el exterior los presos podían estar cómodos, pues los patios eran muy húmedos. La de Zamora, al ser de construcción relativamente reciente, no padecía inconvenientes de ese tipo y señalaban que las mansiones eran sanas. También los informadores

\footnotetext{
${ }^{53}$ Por ejemplo, Pereruela, la Cerecina o Bermillo, declaraban que sólo era segura para retener a "reos de delitos leves" o “de poca consideración”. A.CH.V., Causas Secretas, Caja 46.0003.
} 
de Astorga respondían que su cárcel gozaba de un ambiente saludable. Suponemos que eso ocurría cuando estaban perfectamente reparadas sus instalaciones, pues en ese momento, y a juzgar por la descripción que aparece a continuación - falta de ventanas o techos destrozados-, el frío y la humedad debían de filtrarse por todas las salas del el edificio.

En algunos casos, como es el de la ciudad de León, y al igual que ocurría en el campo de la seguridad, no se trataba de una situación coyuntural, puesto que a lo largo de las dos centurias precedentes son abundantes los documentos en los que se deja constancia de las malas condiciones higiénicas y sanitarias que ofrecía el edificio. En 1659, a raíz del encarcelamiento de tres regidores leoneses, se elaboró un informe en el que se relataban unas condiciones deplorables ${ }^{54}$. Los testimonios fueron lo bastante gráficos como para que podamos hacernos una idea del escenario en el que se desenvolvían los reclusos. Más penoso todavía si nos referimos a las clases populares, pues aquellos gozarían de ciertas ventajas por su nivel económico e influencia social ${ }^{55}$, además de recibir la comida y la ropa que necesitaban de sus familiares.

De todos los testimonios recogidos en la documentación, se desprende que la vida carcelaria de los menos favorecidos sería tan penosa que resulta difícil encontrar un adjetivo para poder calificarla ${ }^{56}$. Pero, a pesar de esa deplorable situación, para muchos de ellos, y para momentos puntuales, el encierro sería la única alternativa de supervivencia ${ }^{57}$.

\footnotetext{
${ }^{54}$ El calabozo, donde fueron recluidos, "está muy asqueroso y muy hediondo". La estancia donde los alojaron era la que estaba destinada a los "condenados a galeras y otros que están por delitos graves", los cuales fueron desplazados a otra contigua. Por lo tanto, si a los regidores, personas con gran influencia social, se les asignó ese espacio, hemos de suponer que el otro se hallaba en unas condiciones aún más deplorables. Las enfermedades que padecían aquellos nobles las achacaban, no a la falta de higiene, sino a que el calabozo "tiene dos puertas muy grandes de reja descubierta y enfrente para ambos lados y en los tres lienzos de el dos ventanas muy grandes de reja sin cubierta y enfrente de la puerta principal está otra ventana grande de reja descubierta por donde se encuentran los aires y vienen a parar a al dicho calabozo..., el cual tiene tan malos suelos que por los agujeros entra el aire frío y en todo él no hay parte sana donde puedan tener sus camas de que les sigue gravísimo daño así a la salud como a sus personas". A.H.P.L., Caja 268.

${ }^{55}$ De ese trato discriminatorio para con los presos nos dejó testimonio, unos años después, la esposa del Alcaide de Toro. Esta mujer le contó al viajero George Borrow, al que se encontró en Valladolid: "Sí; somos muy buenos con ellos; me refiero a los que son caballeros, porque con los que no tienen más que miseria, ¿qué podemos hacer?”. G. Borrow, La Biblia en España, Traducción Manuel Azaña, Madrid, 1921, pp. 67-68.

${ }^{56}$ Respecto a las condiciones de vida en la cárcel durante los siglos XVI y XVII, Vid. H. Roldán Barbero, Historia de la Prisión en España..., pp. 46-48; P. Fraile, Un espacio para castigar. La cárcel y la ciencia penitenciaria en España (s. XVIII-XIX), Barcelona, 1987, pp. 103 y ss.

${ }^{57}$ Cuando las dificultades económicas se agudizaban los que más se significaban en las protestas eran los miembros de los sectores sociales más empobrecidos, puesto que "hasta en las cárceles las condiciones de vida era más soportables que las que tienen fuera”. D. Melossi y M. Pavarini, Cárcel y fábrica..., p. 78 .
} 


\section{Los alcaides}

La mayor parte de las instalaciones dedicadas a la custodia de presos eran de pequeñas dimensiones y se utilizaban circunstancialmente, como también eventuales eran las personas que se encargaban de su vigilancia. Solamente en las cárceles que tenían cierta entidad había un alcaide profesional. A esta figura le dedicaron las preguntas número siete y ocho del interrogatorio que realizó la Chancillería. Se interesaban por dónde vivían, quién les pagaba y qué cantidad.

Responsabilizarse de una cárcel no debía de ser un cargo muy tentador, a pesar de las ganancias que se podían obtener, fundamentalmente por vías poco legales ${ }^{58}$, y de la relativa autonomía ${ }^{59}$ de la que se podía disfrutar. Esas buenas expectativas dejaban de resultar interesantes al sopesar la responsabilidad que se asumía en unas instalaciones como aquellas. Si en ciudades como la de León o Zamora, donde la capacidad de maniobra y extorsión sería mayor que en otras menos concurridas, hubo momentos de graves dificultades para encontrar a una persona capacitada para desempeñar el puesto, en las pequeñas localidades solucionar esa cuestión aún resultaría más complicado. De hecho, en Quintana de Cepeda se solía encargar esta misión al "vecino más miserable de toda la zona porque nadie quiere serlo". Por su parte, en Zamora, a comienzos del siglo XVIII, ante la confusión que se creó tras la renuncia del anterior alcaide, remediaron la situación nombrando a "vecinos del pueblo para que sirvan el empleo" ${ }^{60}$. Esta medida, en principio totalmente circunstancial, se estuvo utilizando, al menos, algo más de una década.

La figura de un alcaide profesional solamente aparece en los núcleos más poblados, caso de León, Zamora, Astorga, Toro o Ponferrada ${ }^{61}$; y en aquellas localidades que por su localización geográfica tenían asignado un cometido concreto, como Alaejos o Alcañices. No obstante, y como hemos señalado, incluso en estos núcleos poblacionales de mayor tamaño, hubo algún momento en que se tuvo que recurrir a los vecinos para que desempeñaran un trabajo de la importancia que tenía este.

En el mundo rural, fundamentalmente, el término fue utilizado de forma ambigua, puesto que la persona que desempeñaba esas funciones en contadas ocasiones tenía únicamente ese cometido. De hecho, y como hemos señalado anteriormente, tanto en las localidades que declaraban tener cárcel como en las que no, lo normal era que la

\footnotetext{
${ }^{58}$ La corrupción institucional era uno de los grandes males de la vida carcelaria. J.L. Heras Santos, "El sistema carcelario de los Austrias en la Corona de Castilla", Stvdia Historica, Vol. VI, 1988, pp. 537 y ss.; E. Villalba Pérez, La Administración de la justicia penal en Castilla y en la Corte a comienzos del siglo XVII, Madrid, 1993, pp. 214 y ss.

${ }^{59} \mathrm{La}$ organización de cárceles las llevó a constituirse como microespacios de poder. P. Oliver Olmo, Cárcel y sociedad represora..., p. 92.

${ }^{60}$ A.H.N. L. 12.483-3.

${ }^{61}$ Ese cargo en Ponferrada era de propiedad señorial. Sobre las tensiones surgidas en la villa berciana por el nombramiento del cargo Vid. F. González González, Cárceles ponferradinas..., pp. 197-219.
} 
tarea de vigilancia de los detenidos recayera en un vecino o en un oficial del concejo, el cual, además de su trabajo principal, debía de asumir el de custodio. Por ejemplo, en la Abadía de Montes o en el Valle de Ancares, ambas en León, el cargo era desempeñado por el juez; en Lorenzana respondían que ejercía de alcaide el alguacil del pueblo, al igual que en Boñar o Cacabelos. Por su parte, en las localidades zamoranas de Villafafila o Maderal esa tarea les correspondía al portero del Ayuntamiento y al guarda de campo, respectivamente, o en Moraleja de Sayago actuaba como tal un regidor. Esas medidas, un tanto improvisadas, y la falta de profesionalidad de los vigilantes, eran factibles por la baja o nula ocupación que tenían las cárceles rurales ${ }^{62}$, que, a su vez, también solían ser de uso provisional.

Las cárceles que tenían a un alcaide profesional, solían disponer de una vivienda para él, en las propias instalaciones. Esas dependencias solían estar formadas por una o dos salas. Por ejemplo, en la de Zamora, que era la de más reciente construcción, la residencia privada del alcaide, que aún era provisional, poseía una cocina y dos pequeños aposentos. En Alaejos, disponía de una cocina y una habitación "decente que le sirve de dormitorio", desde la que podía vigilar a los presos.

Respecto a la dotación del alcaide, encontramos situaciones muy diferentes, que iban en función de la responsabilidad que contraía con el desempeño del cargo y de las disposiciones monetarias de la localidad, siempre procedentes del fondo de propios. En Toro y Zamora les asignaban 100 ducados al año. En Alcañices, el funcionario al que le encomendaban esa tarea, percibía 12 reales por cada preso que salía. En Villafáfila, le daban a mayores al portero del ayuntamiento, por desempeñar también esa actividad, 500 reales. En Peñausende le pagaban trescientos reales, que eran los ingresos que tenía la localidad por arrendar durante el invierno unos pastos.

En la última década del siglo XVIII, concretamente en 1796, se publicó un Auto de Buen Gobierno para la Real Cárcel de León ${ }^{63}$, que debemos encuadrar en el debate ideológico y reformador que sobre este tema había surgido en Europa en la segunda mitad de esa centuria. Entre otras cuestiones, el documento dedicaba al alcaide un número importante de capítulos, en los que se reglamentaba desde el protocolo de organización de la cárcel hasta aspectos relativos a la relación del alcaide con los pre-

\footnotetext{
${ }^{62}$ En las cárceles urbanas la profesionalidad en el ejercicio del cargo no era lo más destacado. Precisamente, la baja capacitación del personal encargado de la custodia de los reos fue otra de las deficiencias sufridas por la cárcel leonesa a lo largo del siglo XVIII y comienzos del XIX. En varios momentos el regimiento se vio obligado a recurrir a los porteros de la ciudad para cubrir interinamente las plazas vacantes de los alcaides, a pesar de sus reticencias a realizar dicha labor. Así sucedió, por ejemplo, en 1771 o 1777. A.H.M.L., Actas municipales, Cajas 75 y 76.

${ }^{63}$ A.M.L., Actas Municipales, Caja 78. A.H.M.L. Caja 78. El esquema del Auto de Buen Gobierno de la ciudad de León tiene muchas semejanzas con el reglamento de la cárcel de Madrid de 1781. P. Trinidad Jiménez, "La reforma de las cárceles en el siglo XIX..., p. 136. Su contenido fue, en gran medida, el reflejo de la nueva concepción de la justicia que estaban fomentando los ilustrados. M.P. Alonso Romero, El proceso penal en Castilla..., pp. 317-335.
} 
$\operatorname{sos}^{64}$. En referencia al primero de esos puntos, se recogían asuntos tales como el mantenimiento del orden interno o el modo de distribuir a los encarcelados, evitando que coincidiesen hombres con mujeres o presos con delitos de distinta gravedad. En cuanto al segundo de los bloques, cabe destacar el recordatorio que le hacían al alcaide sobre que debía de someterse a las autoridades judiciales, la tajante prohibición de percibir cualquier tipo de gratificación fraudulenta, de vender bebidas y alimentos o de no tratar a todos los presos de igual forma ${ }^{65}$. Todas esas disposiciones que recoge el auto nos reflejan la necesidad de acabar con determinadas prácticas abusivas que venían desarrollando, algunas relacionadas con la relajación de sus deberes ${ }^{66} \mathrm{y}$ otras con la usurpación de funciones que eran privativas de la justicia, para su beneficio económico. Este documento emanaba de una real orden, por lo que el comportamiento poco decoroso de los alcaides debía de ser bastante generalizado.

\section{Los presos}

Como es sabido, durante el Antiguo Régimen, los reclusos debían procurarse su propia manutención, lo que les conducía, sobre todo a los que formaban parte de las clases populares, a una situación verdaderamente complicada, pues, además ver como se consumían los pocos bienes de los que disfrutaban, el encierro les impedía acceder a un trabajo. Esa situación se agravaba porque el tiempo de permanencia en la cárcel solía dilatarse ${ }^{67}$, por lo que incluso aquellos que entraban con un cierto nivel de desahogo económico podían acabar pasando necesidades ${ }^{68}$. Antes o después, la gran mayoría terminaban por depender de la caridad para sobrevivir.

\footnotetext{
${ }^{64}$ Pero la realidad carcelaria no siempre se regía por la de superposición entre la teoría legislativa .Vid J. Serna Alonso, Presos y pobres en la España ..., pp. 113-114.

${ }^{65}$ Del nulo respeto que solía hacer los alcaides a este tipo de ordenanzas, de nuevo, nos dejó constancia la esposa del Alcaide de Toro: "La cárcel de Toro es muy divertida: dejamos entrar todo el vino que quieren los presos, mientras tienen dinero para comprarlo y para pagar el derecho de entrada". G. Borrow, La Biblia en España..., p. 68

${ }^{66}$ En este sentido, se puede poner como ejemplo el poco celo con que en ocasiones ejercieron su oficio los alcaides en la ciudad de León. La excesiva permisividad con los reclusos fue causa de alguna fuga. De hecho, en dos ocasiones las huidas estuvieron precedidas de sendos convites, en los que, una vez que el alcaide "estaba embriagado de comida y bebida", los delincuentes no tuvieron dificultad para apoderarse de las llaves y cruzar el umbral hacia la libertad. A.M.L., Actas municipales, Cajas 75 y 76. ${ }^{67}$ A raíz de la fuga de presos que tuvo lugar en la cárcel de León en 1802, éstos pretendían exculparse invocando a que "hay hombres de trece años y medio presos en esta cárcel y de seis años y de tres y de dos los más, sin que se vean adelantadas sus causas un día más que otro". A. CH.V., Causas Secretas, C. 1.641-4.

${ }^{68}$ Estar en la cárcel era como "estar obligatoriamente pagando una pensión". E. Villalba Pérez, La Administración de la justicia penal en Castilla..., p. 216. La estancia en la cárcel era para muchos un salvoconducto de entrada en el mundo de la pobreza. P. Oliver Olmo, Cárcel y sociedad represora..., p. 201. Sobre las denuncias que los ilustrados hicieron de esas demoras, Vid. M.P. Alonso Romero, El proceso penal en Castilla..., p. 325.
} 
A comienzos del siglo XIX, en las cárceles de León y Zamora se utilizaban tres fórmulas para alimentar a los pobres: repartir los gastos de manutención entre los vecinos, recurrir a la limosna y sufragar el alimento a costa de los bienes de propios. Esta última fue la menos frecuente, puesto que para garantizar su viabilidad era necesario que el ayuntamiento o el concejo disfrutaran de ingresos. La mayor parte de las localidades que declaraban actuar de esta forma estaban situadas en la montaña leonesa, dado que en aquella zona los vecinos poseían unas rentas anuales más o menos importantes, derivadas del arriendo de sus agostaderos a las merinas. Es el caso de Abelgas de Luna, Cofiñal o Pinos y San Emiliano. Por el contrario, las otras dos fórmulas para alimentar a los presos fueron más populares. En las localidades zamoranas de Figueruela de Sayago, San Vicente del Barco, Mogatar, Perilla o Montamarta, respondían que el alimento de los presos corría a costa de su familia y para los pobres y forasteros se realizaban repartos entre los vecinos. En Fadón señalaban que solamente tenían que preocuparse del alimento de los forasteros, pues "solo los que pasan para ir a la capital o si a algún vecino lo arrestan un par de horas y para estos nunca falta la misericordia de Dios entre los vecinos". No obstante, hemos de tener en cuenta que la gran mayoría de las cárceles eran de pequeñas dimensiones, que en muy pocas ocasiones estuvieron ocupadas y, cuando así fue, los reos solían ser de la propia localidad, por lo tanto, proporcionar alimento a los detenidos no tendría que representar un grave problema a la justicia local. En cambio sí pasaría a considerarse como tal cuando se tenía que afrontar la de las cuerdas de reos que iban tránsito, cuyo volumen podía ser relativamente importante. En Fresno el Viejo se recogen ambas situaciones y la forma de resolverlo era la siguiente: "como la mayoría son del pueblo se mantienen de sus bienes y los de su familia, para los que pasan a Salamanca o Valladolid, la justicia pide por el pueblo". Por su parte, la información sobre los alimentos que ofrecían a los presos es muy escasa. Las respuestas más completas fueron las de Roales y Grajal de Campos. En la primera les proporcionaban pan y tocino, procedente de la caridad de los vecinos; y en la otra "media libra de menestra 2 veces al día de habas alubias, garbanzos, lentejas o guisantes y medio pan cada día".

Alimentar a los presos se convirtió en un verdadero problema, por lo que algunas localidades, para librarse de esa obligación, los enviaban a las cárceles de la ciudad o villas importantes, alegando que las suyas no eran seguras. Así nos lo señalaron las autoridades de la ciudad de Toro. Añadían que esa conducta les ocasionaba verdaderos problemas, debido a que era frecuente que los pueblos de procedencia no les remitían ningún alimento ni dinero para mantener a esos reos, a pesar de la obligación que tenían de hacerlo. En la cárcel de esta ciudad no se proporcionaba a los presos ninguna ración, les daban entre 1,5 y 2 reales al día ${ }^{69}$ para mantenerse. Esa asignación la com-

\footnotetext{
${ }^{69}$ Esta cantidad podía variar, pues cuando se trataba de recursos trasladados, era la justicia del pueblo de origen quien la estipulaba, eso sí, siempre y cuando enviara el dinero.
} 
pletaban con lo que obtenían pidiendo a través de las rejas y las limosnas que les llegaban por otros cauces.

A su vez, ese sistema por el que los pueblos tenían que costear los alimentos de los delincuentes que apresaban, ya fuera en su propia cárcel o en aquella a la que los remitieran, podía representar un peligro, ya que podía retraer a sus justicias a la hora de actuar. A esa conducta hacían referencia en Zamora. En esa ciudad, para intentar poner remedio al problema, no pedían dinero a las justicias locales del pueblo de procedencia del reo, sino que se hacían cargo de su manutención ${ }^{70}$. Cuando se les agotaban los recursos, tanto los procedentes de las penas de cámara como los de propios, realizaban repartos entre todos los pueblos del partido. A los presos se les proporcionaban una libra de pan y 28 maravedíes al día.

Desde el terreno de la filantropía, particulares e instituciones eclesiásticas desarrollaron una importante labor social. Por ejemplo, en la ciudad de León todos los presos pobres, sin que existiera ningún criterio excluyente ${ }^{71}$, recibían, además del socorro municipal, las limosnas del obispo, de comunidades religiosas o de particulares $^{72}$. Todas esas ayudas eran canalizadas a través del "protector de pobres" 73 . Ese cargo lo ostentaba un regidor que cada año nombraba el cabildo municipal, el cual, además de vigilar para remediarles las necesidades materiales que pudieran padecer, debía de "instruirlos en las causas por las que se hallan presos"74. En Toro, tales funciones correspondían al regidor "comisario protector de la cárcel", que también se encargaba de supervisar la fase procesal por la que atravesaban las causas de los encarcelados, a fin de que no se demorara la sentencia.

Respecto a la caridad particular para con los reos pobres, una vía de canalización era a través de las cofradías, algunas de las cuales tenían esa línea de atención como prioritaria $^{75}$. Es el caso de la Cofradía zamorana de Nuestra Señora de Piedad y pobres de la cárcel o de la ponferradina del Socorro de los Presos Pobres de la Cárcel ${ }^{76}$. Esta

\footnotetext{
70 “... por no gravar considerablemente a los vecinos de donde eran naturales los reos, para que no contrajesen de prenderlos, especialmente a los ladrones". A.CH.V., Causas Secretas, Caja 46.003.

${ }^{71}$ Criterios restrictivos a la hora de recibir esas ayudad aparecen, por ejemplo, ente los reos socorridos por la misericordia de Coimbra. M. A. Lopes, Pobreza, Asistencia..., p. 569.

${ }^{72}$ Respecto a algunas de las ayudas que recibían los presos zamoranos a comienzos de la Edad Moderna, Vid. F.J. Lorenzo López, "Beneficencia y obras pías en los testamentos zamoranos del siglo XVI", Actas del primer congreso de la historia de Zamora, Tomo 3, Zamora, 1991, pp. 631-640, 639.

${ }^{73}$ Esta misma figura, con otros nombres pero prácticamente con los mismos cometidos, aparece en otras ciudades. Para Sevilla, vid. E. Gacto Fernández, "La vida en las cárceles españolas en la época de los Austrias", Historia 16, extra VII, 1978, pp. 11-46.

${ }^{74}$ A.H.M.L., Caja 75.

${ }^{75}$ Asociaciones similares las había en Toledo o Córboba. I. Bazán Díaz, “Crimen y castigo en la Edad Media hispana. La cárcel un 'espacio del mal'”, L'Espai del mal, Lleida, 2005, pp. 313-315. Estas asociaciones tenían un doble objetivo, practicar la generosidad y modificar el comportamiento moral de los presos. P. Trinidad Fernández, La defensa de la sociedad..., p. 126.

${ }^{76}$ F. González González, Cárceles ponferradinas ..., p. 275.
} 
última se fundó en 1568 para de aliviar las necesidades de los presos ${ }^{77}$. Los cofrades, por turno, pedían limosna dos días a la semana, o más si fuera necesario, y con lo recaudado elaboraban la comida que ofrecían a los reclusos dos veces al día. Otro de los campos de actuación de esta hermandad era agilizar los procesos judiciales de los reos, por lo que, en cierta medida, cumplían una función similar a las misericordias portuguesas, en su vertiente asistencial carcelaria ${ }^{78}$. También otras hermandades, aunque no tuvieran a los reos como centro de su actividad, abrieron una línea de asistencia para con ellos. Por ejemplo, en el reglamento de la leonesa de Nuestra Señora de las Angustias y Soledad, se recogía el ofrecer a los reclusos, en las tres pascuas del año, una "comida moderada" servida por los oficiales ${ }^{79}$. A su vez, también hemos encontrado alguna Obra Pía que tenía, entre otros cometidos caritativos, el de socorrer a los presos pobres, como fue la fundada por el sacerdote D. Fernando González de la Huerga, en la localidad zamorana de San Cristóbal de las Entreviñas ${ }^{80}$.

\section{Conclusiones finales}

A comienzos del siglo XIX, y a nivel general, las cárceles que estaban en funcionamiento en las provincias de León y Zamora no reunían las condiciones necesarias para cumplir de forma eficaz con su cometido. De ahí que las fugas fueran una constante en esos establecimientos. Posiblemente, en muchos casos, el estado de ruina sería consecuencia directa de la Guerra de Independencia, en otros solamente se habría acentuado y en la mayoría vendría arrastrándose de etapas anteriores. Determinante en esos casos fue la antigüedad de los edificios y la falta de caudales para poder repararlas. No obstante, y fundamentalmente en el mundo rural, más que de falta de caudales, pues en esos casos podrían suplirse con las hacenderas que recogen las ordenanzas concejiles, hemos de hablar de desidia, que surgiría por la falta de uso. Lógicamente, esa precariedad afectaba tanto las infraestructuras como a las condiciones de habitabilidad, sobre las cuales, y por diversos motivos, apenas había tenido incidencia el higienismo ilustrado.

Por otro lado, y a pesar de todas las propuestas que habían ido surgiendo a lo largo de la Edad Moderna para mejorar las condiciones de los reos, todo parece indicar que esas habían tenido un alcance muy limitado. Los alcaides, a tenor de los autos que

\footnotetext{
77 En el trabajo de Enrique Sanz Delgado, "Las viejas cárceles" se recogen un buen número de instituciones de caridad que a lo largo de la Edad Moderna surgieron en las ciudades y villas para llevar amparo y ejercer el auxilio a los presos.

${ }^{78}$ M.T. Escocard de Oliveira, "As misericórdias e a assistência aos presos", Cadernos do Noroeste, Vol II-2, 1998, pp. 65-81; M.M. Lobo de Araújo, “ Pobres nas malhas da lei: a assistência aos presos nas misericórdias de Vila Viçosa e Ponte de Lima”, Cadernos do Noroeste, Vol II-2, 1998, pp. 83-114.

${ }^{79}$ También el regimiento mostraba una consideración especial para con ellos la noche de navidad y el día de año nuevo. A.H.M.L., Caja 729.

${ }^{80}$ A.H.D.Z., 105/28.
} 
publicaron los regimientos, seguían ejerciendo una autoridad arbitraria, mientras que, por otro lado, hacían dejación de sus funciones, compartiendo con los reos comida y bebida. A su vez, el sistema que se utilizado para cubrir las necesidades alimenticias de los presos, no sólo resultaba dañino para ellos, sino también para la propia sociedad, puesto que era muy propicio para provocar una relajación en la actividad de la justicia. 